\title{
Büyükler Serbest Stil Türkiye Şampiyonasına Katılan Erkek Güreşçilerin Kilo Düşme Profillerinin İncelenmesi
}

\author{
Kürşat ÇİMEN ${ }^{*}$ iD, Kemal GÖRAL ${ }^{2}$ \\ ${ }^{1}$ Muğla Sıtkı Koçman Üniversitesi, Sağlık Bilimleri Enstitüsü, Muğla. \\ ${ }^{2}$ Muğla Sttkı Koçman Üniversitesi, Spor Bilimleri Fakültesi, Muğla.
}

\section{Orijinal Makale}

Gönderi Tarihi: 22.09.2020
Kabul Tarihi: 20.11.2020
DOI: $10.25307 / j s s r .797727$

Online Yayın Tarihi: 31.12 .2020

\section{Öz}

Bu çalışmanın amacı, Büyükler Serbest Stil Türkiye Şampiyonasına katılan erkek güreşçilerin kilo düşme profillerinin farklı değişkenler açısından incelenmesidir. Araştırma grubu, Büyükler Türkiye Güreş Şampiyonasına katılmış sporcular arasından

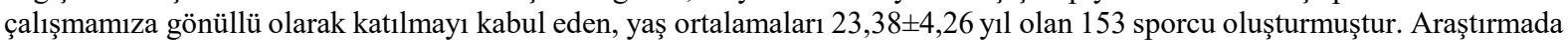
veri toplama aracı olarak, Yarar, Eroğlu, Üzüm ve Polat (2016) tarafından geliştirilen "Sporcu Kilo Düşme Yöntemleri ve Etkileri Ölçeği"nden yararlanılmıştır. Araştırmada, tüm sıkletlerdeki güreşçilerin büyük çoğunluğu, müshil, diyet ve idrar söktürücü gibi haplar kullanmayı tercih etmediklerini belirtirlerken, kilo düşme yöntemlerinden diyet alt boyutunda yer alan yă̆ tüketiminin azaltılmasının en çok tercih edilen cevap olduğu belirlenmiştir. Araştırmada elde edilen bulgulara göre, sıkletler arası alt boyutların karşılaştırılmasında sadece diyet alt boyutu içerisinde yer alan "Karbonhidrat tüketimini azaltırım" cevapları arasında anlamlı bir farka rastlanmıştır. Farklılı̆̆ yaratan grubun ise ağır sıklet güreşçiler olduğu, hem hafif sıklet hem de orta sıklet güreşçiler ile ağır sıklet güreşçiler arasında farklılık bulunduğu belirlenmiştir $(\mathrm{p}<.05)$. Sonuç olarak, güreşçilerin kilo düşme stratejisi olarak, genellikle vücuttan yağ kaybı, sıvı kaybı, yiyecek ve karbonhidrat tüketimini azaltma eğilimde olma gibi yeterli ve dengeli beslenme açısından oldukça önemli konular üzerinde yoğunlaştıklarının görülmesinden hareketle, sporcu performansını etkileyen fizyolojik ve psikolojik faktörlerin bu etkenlerden önemli ölçüde etkilendiği düşüncesiyle, performans sporcuları ve antrenörlere kilo düşme yöntemleri ve kilo kontrolü hakkında uzmanlar tarafından seminerler verilmesi, bilgilendirilmesi ve özellikle sıklet sporlarında müsabık performans sporcusu yetiştiren antrenörlerin bu seminerlere katılımlarının zorunlu hale getirilmesinin, sporcuların ulaşmak istedikleri yüksek performans noktasına erişebilmeleri açısından oldukça fayda sağlayacağı söylenebilir.

Anahtar kelimeler: Güreş, Serbest stil, Kilo düşme.

\section{Examination of Weight Loss Profile of the Male Wrestlers Participating Turkey Seniors Freestyle Championship}

\begin{abstract}
The aim of this study was to investigate the male wrestlers participated in the championship in Turkey's senior age categories according to weight category of the weight loss profile. The research group of the study consisted of 153 wrestlers participated in the seniors' free style Turkey wrestling Championships. The average age of the volunteer wrestlers participating in the study was $23.38 \pm 4.26$ years. In the research, "Athlete Weight Loss Methodology and Effects Scale" developed by Yarar, Eroğlu, Üzüm and Polat (2016) was used. The vast majority of the wrestlers stated that they did not prefer to use pills such as laxatives, diets and diuretics. In the diet sub-dimension, reduction of fat consumption is the most preferred answer for weight loss methods. According to the findings obtained in the study, in the comparison between the sub-dimensions weights, only difference was found in the "I decrease the carbohydrate consumption" responses in the diet sub-dimension. There are differences between both light weight and medium weight wrestlers and heavy weight wrestlers $(\mathrm{p}<.05)$. Consequently, wrestlers generally focus on weight reduction strategy such as fat reduction, fluid loss, food and carbohydrate consumption reduction. However, these issues are very important in terms of adequate and balanced nutrition. With the idea of physiological and psychological factors that impact athlete's performance is affected by such factors, for reaching the peak performance, it can be beneficial to organizing seminars by experts about weight control and weight losing methods for performance athletes and coaches, making these seminars compulsory for coaches who educate competent athletes, especially in individual sports.
\end{abstract} Key Words: Wrestling, Freestyle, Weight loss.

\footnotetext{
* Sorumlu yazar: Kürşat Çimen, E-posta: cimen.kursatt@ gmail.com

* Bu çalışma, Kürşat ÇíMEN tarafından, 2020 yılında Muğla Sitkı Koçman Üniversitesi Sağlık Bilimleri Enstitüsü Antrenörlük Eğitimi Anabilim Dalında tamamlanan yüksek lisans tezinden türetilmiştir.
} 


\section{GíRiş}

İkili bir mücadele sporu olarak tanımlanan güreşte her sporcu rakibini yenmeye çalışır. Bunun için de iyi şekilde oluşmuş bir teknik ve kondisyona sahip olmanın yanında, cesaretli bir şekilde saldırı ve hücum yapabilecek taktik beceriye de sahip olunmalıdır. Güreş müsabakasındaki amaç, spora özgü beceri ve tekniklerin kullanılarak rakibe karşı hakimiyet kurabilmektir Güreş sporu sadece yeteneğin değil, aynı zamanda güreşçilerin kısa sürede en hızlı hamleyi yapmasını gerektiren bir spordur (Demirci, 1995; Çamçakal, Pepe ve Altın, 2014). Güreş branşında, sezon boyunca devam eden antrenmanlarla güreşçilerin kuvvet, esneklik, sürat, reaksiyon gibi özelliklerinin geliştirilerek müsabakaların devam ettiği sezon süresince üst düzeyde tutulabilmesi ve istenilen en yüksek performansa ulaşmaları hedeflenir (Cicioğlu, Kürkçü, Eroğlu, ve Yüksek, 2007).

Sporcularda vücut ağırlığı, bir sporcunun hızına, dayanıklılığına ve gücüne, vücutta bulunan yağsız doku ile yağ ve su miktarı (vücut kompozisyonu) ise kuvvet ve çevikliğe etki etmektedir. Güreş sporcuları, genellikle belirli bir sıklette rakiplerine karşı üstün gelmek için avantaj elde etmek adına kilo düşerler. Bu durumda, birçok sporcu kilo düşmek için sağlıksız yöntemlere başvurmaktadır. Bu da sportif performansın düşmesinin yanı sıra çeşitli tıbbi sorunları da beraberinde getirebilir. Diğer taraftan, kilo düşme sağlıklı bir biçimde izlenerek gerçekleştirildiğinde güreş sezonunda sporcular daha güçlü ve daha sağlıklı olabilirler (Buschmann ve Cuff, 2016; Ersoy ve Hasbay, 2008).

Vücut ağırlığında azaltma, ağırlık döngüsü ve hızlı vücut kütle kaybına da benzer olan hızlı kilo düşme, sporcular tarafından hedeflenen sıkletlerde avantaj elde ederek başarılı olabilmek için en yaygın şekilde kullanılan stratejilerden biridir (Xiong, Xian, Karppaya, Jin ve Ramadas, 2017). Sporcularda hızlı kilo düşme, avantajdan çok dezavantajlı bir durum ortaya çıkarabilir. Hemen hemen hiçbir sporcu organizma olarak fazla su kaybına uğradığı zaman en iyi performansına ulaşamayacaktır. Bilinçsiz bir şekilde meydana gelen zayıflama, yăg dokularında olduğu kadar kas dokularında da kayıplara sebebiyet vermektedir (İşler, 2012). Müshil ilaçlarının ve diüretiklerin kullanımı ve kusma gibi yöntemler sağlıksız şekilde kilo düşme yöntemleri olarak ifade edilmektedir (Çatıkkaş, 2016).

Güreş sporunda, belirli bir sıklette sporcuların rakiplerine karşı üstün gelmek için avantaj elde edebilmek ya da istenilen sıklette yarışabilmek adına kilo düştükleri, böylesi durumlarda da, birçok sporcunun hızlı kilo düşebilmek için farklı yöntemlere başvurdukları düşüncesinden hareketle, bu çalışma, Büyükler Serbest Stil Türkiye Şampiyonasına katılan erkek güreşçilerin kilo düşme profillerinin farklı değişkenler açısından incelenmesi amacıyla yapılmıştır.

\section{YÖNTEM}

Araştırma Grubu: Bu çalışma, Türkiye şampiyonasına katılan büyükler kategorisindeki erkek güreşçilerin kilo düşme profillerinin sıkletlere göre incelenmesi amacıyla gerçekleştirilmiştir. $\mathrm{Bu}$ çalışmada araştırma grubunu, Büyükler Türkiye Güreş Şampiyonasına katılmış sporcular

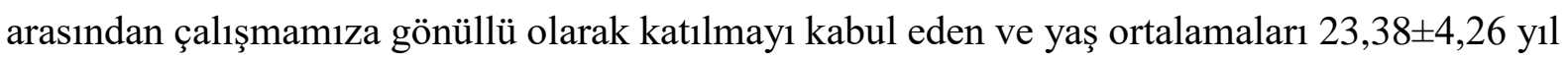
olan 153 sporcu oluşturmuştur. 
Verilerin Toplanması: Araştırmada veri toplama aracı olarak, Yarar, Eroğlu, Üzüm ve Polat (2016) tarafından geliştirilen "Sporcu Kilo Düşme Yöntemleri ve Etkileri Ölçeği”"nden yararlanılmıştır. Ölçekte, Fizyolojik etkiler, Psikolojik etkiler, Ergojenik yardım, Diyet ve Sıvı kaybı olmak üzere 5 alt boyut yer almaktadır. Beşli likert tipi puanlama kriterine (1=Hiçbir zaman, 2=Nadiren, 3=Ara sıra, 4=S1k S1k, 5=Her zaman) göre değerlendirilerek puanlanmakta olan ölçeğin Cronbach's alpha güvenirlik katsayısı $\alpha=0.74$ tespit edilmiştir (Yarar vd., 2016).

Ölçekte, "sporcunun kilo düşerken kas krampları, kalp çarpması, solunum güçlüğü, sakatlık yaşama, vücut 1sısının artışı fizyolojik etkilerini yaşama derecesinin” ölçüldüğü fizyolojik etki; "sporcunun kilo düşerken spor yapma isteği, sinirlilik hali, yorgunluk, stres durumu ve performans düzeylerine ilişkin kendisini psikolojik olarak nasıl hissettiğine yönelik durumunun" ölçüldüğü psikolojik etki; "sporcunun kilo düşerken idrar söktürücüler, diyet hapları vb. maddeleri kullanma derecelerinin" ölçüldüğü ergojenik yardımcılar; "sporcunun kilo düşerken diyet yöntemlerinden yağ, karbonhidrat ve yiyecek tüketiminin azaltılma düzeyini" ölçmekte olan diyet; sporcunun kilo düşerken saunaya girerek terleme, tükürme ve yağmurlukla koşu yapma gibi eylemler ile ne derece kilo düşmeye yöneldiğinin" ölçüldüğü sıv1 kaybı alt boyutları bulunmaktadır (Yarar vd., 2016).

Araştırmaya başlamadan önce, Türkiye Güreş Federasyonundan çalışmaya yönelik gerekli izinler alınmıştır. 19-22 Aralık 2019 tarihlerinde gerçekleştirilen Büyükler Türkiye Şampiyonasına katılmış olan güreşçilerin listesine, Türkiye Güreş Federasyonu resmi web sitesinden ulaşıldıktan sonra, anketler bizzat araştırmacı tarafından güreş kamp merkezlerine gidilerek güreşçilerin dinlenme saatlerinde yaptırılmıştır.

Araştırma Etiği: Araştırmanın etik onayı ise, Muğla Sıtkı Koçman Üniversitesi İnsan Araştırmaları Etik Kurulu'ndan 14.02.2020 tarihli ve 27 karar numarası ile sağlanmıştır.

Verilerin Analizi: Elde edilen verilerin istatistiksel analizinde SPSS (version 20) paket programı kullanılmıştır. Verilerin yüzde, frekans ve ortalama değerleri belirlenmiş olup, verilerin normal dağılım gösterip göstermediğini belirlemek amacıyla Kolmogorov Smirnov testi yapıldığında, elde edilen verilerin normal dağılım göstermediği tespit edilmiştir. Gruplar arasındaki karşılaştırmalarda parametrik olmayan testlerden Kruskall Wallis testinden ve farklılığ1 yaratan grubun belirlenmesinde ise post hoc testlerinden Tamhane's T2 testinden yararlanılmıştır. Değişkenler arasındaki ilişkilerin incelenmesinde ise Spearman korelasyon testi kullanılmıştır. Anlamlılık düzeyi $\mathrm{p}<0.05$ olarak kabul edilmiştir. 
Çimen, K. ve Göral, K. (2020). Büyükler serbest stil türkiye şampiyonasına katılan erkek güreşçilerin kilo düşme profillerinin incelenmesi. Spor Bilimleri Araşttrmaları Dergisi, 5(2), 188-201.

\section{BULGULAR}

Araştırmada elde edilen bulgular 1şığında aşağıda yer alan tablolar oluşturulmuş ve yorumlanmıştır.

Tablo 1. Araştırmaya katılan güreşçilerin yaş, boy uzunluğu ve spor yaşlarına ilişkin demografik özellikleri

\begin{tabular}{lccc}
\hline Değişkenler & N & X & S \\
\hline Yaş (yıl) & 153 & 23,38 & 4,26 \\
\hline Boy Uzunluğu (cm) & 153 & 175,5 & 7,03 \\
\hline Spor yaşı & 153 & 10,45 & 3,31 \\
\hline
\end{tabular}

Araştırmaya katılan güreşçilerin yaş ortalamaları $23,38 \pm 4,26$ y1l; boy uzunluğu ortalamaları $175,5 \pm 7,03 \mathrm{~cm}$, spor yaşı ortalamaları ise $10,45 \pm 3,31$ yıl olarak bulunmuştur.

Tablo 2. Araştırmaya katılan güreşçilerin sıkletlere göre dağılımı

\begin{tabular}{lcc}
\hline Değişkenler & F & \% \\
\hline Hafif Sıklet (57-70 kg) & 72 & 47,1 \\
Orta Sıklet (74-86 $\mathbf{~ k g )}$ & 44 & 28,8 \\
Ağır Sıklet (92-125 kg) & 37 & 24,2 \\
Toplam & 153 & 100,0 \\
\hline
\end{tabular}

Araştırmaya katılan güreşçilerin $\% 47,1$ 'ini hafif sıklet, $\% 28,8$ 'ini orta sıklet, $\% 24,2$ 'sini ise ağır sıklet sporcular oluşturmaktadır.

Tablo 3. Ağır sıklet güreşçilerinin verdikleri cevapların dağılımlarını gösteren tablo

\begin{tabular}{|c|c|c|c|c|c|c|}
\hline Alt boyutlar & & $\begin{array}{l}\text { Hiçbir } \\
\text { Zaman }\end{array}$ & Nadiren & $\begin{array}{l}\text { Ara } \\
\text { sira }\end{array}$ & $\begin{array}{l}\text { Sik } \\
\text { sık }\end{array}$ & $\begin{array}{c}\text { Her } \\
\text { zaman }\end{array}$ \\
\hline \multirow{3}{*}{ Diyet } & Yiyecek tüketimini azaltırım & 2,7 & 27,0 & 16,2 & 18,9 & 35,1 \\
\hline & Karbonhidrat tüketimini azaltırım & - & 2,7 & 24,3 & 37,8 & 35,1 \\
\hline & Yağ tüketimini azaltırım & 2,7 & 8,1 & 16,2 & 18,9 & 54,1 \\
\hline \multirow{3}{*}{ Sivı kaybı } & Yağmurlukla koşu yaparım & 5,4 & 27,0 & 27,0 & 29,7 & 10,8 \\
\hline & Saunaya girerim & 29,7 & 5,4 & 29,7 & 32,4 & 2,7 \\
\hline & Tükürerek kilo kaybederim & 89,2 & 8,1 & 2,7 & - & - \\
\hline \multirow{3}{*}{$\begin{array}{c}\text { Ergojenik } \\
\text { yardımcılar }\end{array}$} & Müshil hapları (ishal kesici) kullanırım & 94,6 & 5,4 & - & - & - \\
\hline & Diyet hapları kullanırım & 89,2 & 8,1 & 2,7 & - & - \\
\hline & İdrar söktürücü haplar kullanırım & 83,8 & 13,5 & 2,7 & - & - \\
\hline \multirow{5}{*}{$\begin{array}{c}\text { Fizyolojik } \\
\text { etki }\end{array}$} & Kas krampları yaşarım & 43,2 & 40,5 & 10,8 & 2,7 & 2,7 \\
\hline & Vücut 1sim artar & 37,8 & 40,5 & 18,9 & 2,7 & - \\
\hline & Kalp çarpıntısı yaşarım & 43,2 & 48,6 & 8,1 & - & - \\
\hline & Solunum güçlüğü çekerim & 37,8 & 37,8 & 16,2 & 8,1 & - \\
\hline & Sakatlık yaşarım & 8,1 & 54,1 & 27,0 & 8,1 & 2,7 \\
\hline \multirow{5}{*}{$\begin{array}{c}\text { Psikolojik } \\
\text { etki }\end{array}$} & Aşırı sinirli hale gelirim & 13,5 & 40,5 & 24,3 & 16,2 & 5,4 \\
\hline & Aşırı yorgun hissederim & 2,7 & 37,8 & 32,4 & 16,2 & 10,8 \\
\hline & Performansım düşer & 5,4 & 40,5 & 37,8 & 13,5 & 2,7 \\
\hline & Strese girerim & 10,8 & 43,2 & 29,7 & 10,8 & 5,4 \\
\hline & Spor yapma isteğim azalır & 13,5 & 43,2 & 32,4 & 10,8 & - \\
\hline
\end{tabular}

Ağır sıklet güreşçilerin verdikleri cevaplar incelendiğinde; Diyet alt boyutu açısından, \%35,1'i her zaman yiyecek tüketimini azalttığını, \%37,8'i sık sık ve \%35,1'i her zaman karbonhidrat tüketimini azalttığını, \%54,1'i her zaman yağ tüketimini azalttığını belirtmiştir. Sıvı kaybı alt boyutu açısından, güreşçilerin \%29,7'sinin sık s1k yağmurlukla koşuyu, \%32,4'ünün ise sık sık saunaya girmeyi tercih ettikleri görülmektedir. Ergojenik yardımcılar alt boyutu açısından, 
güreşçilerin \%94,6'sı müshil haplarını, \%89,8'i diyet hapları kullanmayı, \%83,8'i ise idrar söktürücü haplar kullanmayı tercih etmediklerini belirtmişlerdir. Fizyolojik etki alt boyutu açısından, kilo düşme sonrasında güreşçilerin \%43,2'si hiçbir zaman kas krampları yaşamadıklarını, \%40,5'i nadiren vücut 1sısında artış yaşadıklarını, \%48,6'sı nadiren kalp çarpıntısı vakası yaşadıklarını, \%16,2'si ara sıra solunum güçlüğü çektiğini, \%54,1'i ise nadiren de olsa sakatlık yaşadıklarını belirtmişlerdir. Psikolojik etki alt boyutu açısından, kilo düşme sonrasında güreşçilerin, $\% 40,5$ 'i nadiren aşırı sinirli hale geldiğini, \%37,8'i nadiren aşırı yorgun hale geldiğini, $\% 40,5$ 'i nadiren performansının düştüğünü, \%43,2'si nadiren strese girdiğini, \%43,2'si de nadiren spor yapma isteklerinde azalma olduğunu belirtmişlerdir.

Tablo 4. Orta sıklet güreşçilerinin verdikleri cevapların dağılımlarını gösteren tablo

\begin{tabular}{|c|c|c|c|c|c|c|}
\hline Alt boyutlar & & $\begin{array}{l}\text { Hiçbir } \\
\text { Zaman }\end{array}$ & Nadiren & $\begin{array}{l}\text { Ara } \\
\text { sira }\end{array}$ & Sık sık & $\begin{array}{c}\text { Her } \\
\text { zaman }\end{array}$ \\
\hline \multirow{3}{*}{ Diyet } & Yiyecek tüketimini azaltırım & 7,0 & 23,3 & 25,6 & 9,3 & 34,9 \\
\hline & Karbonhidrat tüketimini azaltırım & 4,7 & 20,9 & 32,6 & 23,3 & 18,6 \\
\hline & Yağ tüketimini azaltırım & 2,3 & 9,3 & 27,9 & 23,3 & 37,2 \\
\hline \multirow{3}{*}{ Sıvı kaybı } & Yağmurlukla koşu yaparım & 11,6 & 25,6 & 18,6 & 20,9 & 23,3 \\
\hline & Saunaya girerim & 20,9 & 25,6 & 39,5 & 4,7 & 9,3 \\
\hline & Tükürerek kilo kaybederim & 81,4 & 18,6 & - & - & - \\
\hline \multirow{3}{*}{$\begin{array}{c}\text { Ergojenik } \\
\text { yardımcılar }\end{array}$} & Müshil hapları (ishal kesici) kullanırım & 93,0 & 7,0 & - & - & - \\
\hline & Diyet hapları kullanırım & 86,0 & 11,6 & 2,3 & - & - \\
\hline & İdrar söktürücü haplar kullanırım & 79,1 & 20,9 & - & - & - \\
\hline \multirow{5}{*}{$\begin{array}{c}\text { Fizyolojik } \\
\text { etki }\end{array}$} & Kas krampları yaşarım & 39,5 & 41,9 & 14,0 & 2,3 & 2,3 \\
\hline & Vücut 1sım artar & 30,2 & 34,9 & 32,6 & 2,3 & - \\
\hline & Kalp çarpıntısı yaşarım & 51,2 & 30,2 & 18,6 & - & - \\
\hline & Solunum güçlüğü çekerim & 37,2 & 32,6 & 20,9 & 7,0 & 2,3 \\
\hline & Sakatlık yaşarım & 25,6 & 20,9 & 44,2 & 9,3 & - \\
\hline \multirow{5}{*}{$\begin{array}{c}\text { Psikolojik } \\
\text { etki }\end{array}$} & Aşırı sinirli hale gelirim & 16,3 & 23,3 & 37,2 & 16,3 & 7,0 \\
\hline & Aşırı yorgun hissederim & 9,3 & 20,9 & 46,5 & 18,6 & 4,7 \\
\hline & Performansım düşer & 4,7 & 20,9 & 41,9 & 30,2 & 2,3 \\
\hline & Strese girerim & 14,0 & 20,9 & 44,2 & 18,6 & 2,3 \\
\hline & Spor yapma isteğim azalır & 14,0 & 23,3 & 34,9 & 23,3 & 4,7 \\
\hline
\end{tabular}

Orta sıklet güreşçilerin verdikleri cevaplar incelendiğinde; Diyet alt boyutu açısından, \%34,9'u her zaman yiyecek tüketimini azalttığını, \%32,6'sı ara sıra karbonhidrat tüketimini azalttığını, \%37,2'si ise her zaman yă̆ tüketimini azalttığını belirtmişlerdir. Sıvı kaybı alt boyutu açısından, güreşçilerin \%23,3'ünün her zaman yağmurlukla koşuyu, \%39,5'inin ise ara sıra saunaya girmeyi tercih ettikleri görülmektedir. Ergojenik yardımcılar alt boyutu açısından, güreşçilerin \%93'ünün müshil haplarını, \%86'sının diyet hapları kullanmayı, \%79,1'i ise idrar söktürücü haplar kullanmayı tercih etmediklerini belirtmişlerdir. Fizyolojik etki alt boyutu açısından, kilo düşme sonrasında güreşçilerin \%41,9'u nadiren kas krampları yaşadıklarını, \%34,9'u nadiren vücut ısısında artış yaşadıklarını, \%51,2'si hiçbir zaman kalp çarpıntısı vakası yaşamadıklarını, \%20,9’u ara sıra solunum güçlüğü çektiğini, \%44,2'si ise ara sıra da olsa sakatlık yaşadıklarını belirtmişlerdir. Psikolojik etki alt boyutu açısından, kilo düşme sonrasında güreşçilerin, \%37,2'si ara sıra sinirli hale geldiğini, \%46,5'i ara sıra aşırı yorgun hale geldiğini, $\% 41,9$ 'u ara sıra performansının düştügünü, $\% 44,2$ 'si ara sıra strese girdiğini, \%34,9'u da ara sıra spor yapma isteğinde azalma olduğunu belirtmiştir. 
Çimen, K. ve Göral, K. (2020). Büyükler serbest stil türkiye şampiyonasına katılan erkek güreşçilerin kilo düşme profillerinin incelenmesi. Spor Bilimleri Araşttrmaları Dergisi, 5(2), 188-201.

Tablo 5. Hafif sıklet güreşçilerinin verdikleri cevapların dağılımlarını gösteren tablo

\begin{tabular}{|c|c|c|c|c|c|c|}
\hline Alt boyutlar & & $\begin{array}{l}\text { Hiçbir } \\
\text { Zaman }\end{array}$ & Nadiren & $\begin{array}{l}\text { Ara } \\
\text { sira } \\
\end{array}$ & Sık sık & $\begin{array}{c}\text { Her } \\
\text { zaman }\end{array}$ \\
\hline \multirow{3}{*}{ Diyet } & Yiyecek tüketimini azaltırım & 9,6 & 24,7 & 21,9 & 17,8 & 26,0 \\
\hline & Karbonhidrat tüketimini azaltırım & 4,1 & 21,9 & 27,4 & 24,7 & 21,9 \\
\hline & Yağ tüketimini azaltırım & 2,7 & 17,8 & 23,3 & 20,5 & 35,6 \\
\hline \multirow{3}{*}{ Sıvı kaybı } & Yağmurlukla koşu yaparım & 4,1 & 21,9 & 34,2 & 11,0 & 28,8 \\
\hline & Saunaya girerim & 15,1 & 30,1 & 30,1 & 15,1 & 9,6 \\
\hline & Tükürerek kilo kaybederim & $\mathbf{7 4 , 0}$ & 19,2 & 2,7 & - & 4,1 \\
\hline \multirow{3}{*}{$\begin{array}{c}\text { Ergojenik } \\
\text { yardımcılar }\end{array}$} & Müshil hapları (ishal kesici) kullanırım & 84,9 & 8,2 & 4,1 & 1,4 & 1,4 \\
\hline & Diyet hapları kullanırım & 87,7 & 6,8 & 4,1 & 1,4 & - \\
\hline & İdrar söktürücü haplar kullanırım & 83,6 & 11,0 & 5,5 & - & - \\
\hline \multirow{5}{*}{$\begin{array}{c}\text { Fizyolojik } \\
\text { etki }\end{array}$} & Kas krampları yaşarım & 41,1 & 38,4 & 19,2 & 1,4 & - \\
\hline & Vücut 1sim artar & 35,6 & 39,7 & 23,3 & 1,4 & - \\
\hline & Kalp çarpıntısı yaşarım & 56,2 & 30,1 & 13,7 & - & - \\
\hline & Solunum güçlüğü çekerim & 43,8 & 28,8 & 19,2 & 8,2 & - \\
\hline & Sakatlık yaşarım & 13,7 & 42,5 & 24,7 & 16,4 & 2,7 \\
\hline \multirow{5}{*}{$\begin{array}{l}\text { Psikolojik } \\
\text { etki }\end{array}$} & Aşırı sinirli hale gelirim & 15,1 & 28,8 & 31,5 & 13,7 & 11,0 \\
\hline & Aşırı yorgun hissederim & 15,1 & 30,1 & 28,8 & 16,4 & 9,6 \\
\hline & Performansım düşer & 8,2 & 27,4 & 31,5 & 23,3 & 9,6 \\
\hline & Strese girerim & 16,4 & 30,1 & 30,1 & 20,5 & 2,7 \\
\hline & Spor yapma isteğim azalır & 16,4 & 41,1 & 24,7 & 13,7 & 4,1 \\
\hline
\end{tabular}

Orta sıklet güreşçilerin verdikleri cevaplar incelendiğinde; Diyet alt boyutu açısından, \%26's1 her zaman yiyecek tüketimini azalttığını, \%27,4'ü ara sıra karbonhidrat tüketimini azalttığını, \%35,6's1 ise her zaman yağ tüketimini azalttığını belirtmişlerdir. Sıvı kayb1 alt boyutu açısından, güreşçilerin \%28,8'inin her zaman yağmurlukla koşuyu, \%30,1'inin ise ara sıra saunaya girmeyi tercih ettikleri görülmektedir. Ergojenik yardımcılar alt boyutu açısından, güreşçilerin \%84,9'unun müshil haplarını, \%87,7'sinin diyet hapları kullanmayı, \%83,6's1 ise idrar söktürücü haplar kullanmayı tercih etmediklerini belirtmişlerdir. Fizyolojik etki alt boyutu açısından, kilo düşme sonrasında güreşçilerin \%38,4'ü nadiren kas krampları yaşadıklarını, \%39,7'si nadiren vücut ısısında artış yaşadıklarını, \%56,2'si hiçbir zaman kalp çarpıntısı vakası yaşamadıklarını, \%19,2'si ara sıra solunum güçlüğü çektiğini, \%24,7'si ise ara sıra da olsa sakatlık yaşadıklarını belirtmişlerdir. Psikolojik etki alt boyutu açısından, kilo düşme sonrasında güreşçilerin, $\% 31,5$ 'i ara sıra sinirli hale geldiğini, $\% 28,8$ 'i ara sıra aşırı yorgun hale geldiğini, $\% 31,5^{\prime} i$ ara sira performansının düştüğünü, $\% 30,1^{\prime}$ i ara sira strese girdiğini, \%24,7’si de ara sıra spor yapma isteğinde azalma olduğunu belirtmiştir. 
Çimen, K. ve Göral, K. (2020). Büyükler serbest stil türkiye şampiyonasına katılan erkek güreşçilerin kilo düşme profillerinin incelenmesi. Spor Bilimleri Araşttrmaları Dergisi, 5(2), 188-201.

Tablo 6. Güreşçilerin sıkletlerine göre verdikleri cevapların (Diyet, Sıvı Kaybı, Ergojenik yardımcılar) karşılaştırılması

\begin{tabular}{|c|c|c|c|c|c|}
\hline Alt boyutlar & & Sıkletler & Ort.Sira & $\mathbf{x}^{2}$ & $\mathbf{p}$ \\
\hline \multirow{9}{*}{ Diyet } & \multirow{3}{*}{ Yiyecek tüketimini azaltırım } & Hafif S1klet (57-70 kg) & 72,53 & \multirow{3}{*}{1,573} & \multirow{3}{*}{,456 } \\
\hline & & Orta Siklet (74-86 kg) & 79,55 & & \\
\hline & & Ağır S1klet ( 92-125 kg) & 82,66 & & \\
\hline & \multirow{3}{*}{ Karbonhidrat tüketimini azaltırım } & Hafif Siklet (57-70 kg) & 72,03 & \multirow{3}{*}{10,756} & \multirow{3}{*}{, $005 *$} \\
\hline & & Orta Siklet (74-86 kg) & 68,35 & & \\
\hline & & Ağır Siklet ( 92-125 kg) & 96,96 & & \\
\hline & \multirow{3}{*}{ Yağ tüketimini azaltırım } & Hafif Siklet (57-70 kg) & 72,83 & \multirow{3}{*}{3,670} & \multirow{3}{*}{, 160} \\
\hline & & Orta Siklet (74-86 kg) & 74,10 & & \\
\hline & & Ağır S1klet ( 92-125 kg) & 88,55 & & \\
\hline \multirow{9}{*}{ Sivı kaybı } & \multirow{3}{*}{ Yağmurlukla koşu yaparım } & Hafif Siklet (57-70 kg) & 80,07 & \multirow{3}{*}{,799 } & \multirow{3}{*}{671} \\
\hline & & Orta S1klet (74-86 kg) & 75,72 & & \\
\hline & & A ğır Sıklet ( 92-125 kg) & 72,55 & & \\
\hline & \multirow{3}{*}{ Saunaya girerim } & Hafif Siklet (57-70 kg) & 79,20 & \multirow{3}{*}{1,429} & \multirow{3}{*}{489} \\
\hline & & Orta S1klet (74-86 kg) & 70,51 & & \\
\hline & & Ağır S1klet ( 92-125 kg) & 80,43 & & \\
\hline & \multirow{3}{*}{ Tükürerek kilo kaybederim } & Hafif Siklet (57-70 kg) & 81,71 & \multirow{3}{*}{4,066} & \multirow{3}{*}{, 131} \\
\hline & & Orta S1klet (74-86 kg) & 75,17 & & \\
\hline & & Ağır Siklet ( 92-125 kg) & 69,82 & & \\
\hline \multirow{9}{*}{$\begin{array}{c}\text { Ergojenik } \\
\text { yardımcılar }\end{array}$} & \multirow{3}{*}{ Müshil hapları (ishal kesici) kullanırım } & Hafif Siklet $(57-70 \mathrm{~kg})$ & 80,86 & \multirow{3}{*}{3,705} & \multirow{3}{*}{, 157} \\
\hline & & Orta Siklet (74-86 kg) & 74,05 & & \\
\hline & & Ağır Siklet ( 92-125 kg) & 73,00 & & \\
\hline & \multirow{3}{*}{ Diyet hapları kullanırım } & Hafif Siklet (57-70 kg) & 77,20 & \multirow{3}{*}{, 147} & \multirow{3}{*}{,929 } \\
\hline & & Orta Siklet (74-86 kg) & 77,78 & & \\
\hline & & Ağır S1klet ( 92-125 kg) & 75,68 & & \\
\hline & \multirow{3}{*}{ İdrar söktürücü haplar kullanırım } & Hafif Siklet $(57-70 \mathrm{~kg})$ & 76,58 & \multirow{3}{*}{, 207} & \multirow{3}{*}{,902 } \\
\hline & & Orta Siklet (74-86 kg) & 78,64 & & \\
\hline & & Ağır Siklet ( 92-125 kg) & 75,86 & & \\
\hline
\end{tabular}

Araştırmaya katılan güreşçilerin, diyet, sıvı kaybı ve ergojenik yardımcılar alt boyutlarında yer alan sorulara verdikleri cevaplar sonucunda, sıkletler arası karşılaştırmalarda sadece diyet alt boyutu içerisinde yer alan "Karbonhidrat tüketimini azaltırım" cevapları arasında anlamlı bir farka rastlanırken ( $\mathrm{p}<.05)$, "Yiyecek tüketimini azaltırım" ve "Yağ tüketimini azaltırım" cevapları arasında ise bir farklılık bulunamamıştır ( $\mathrm{p}>.05)$.

Diğer taraftan, sıvı kaybı alt boyutunda yer alan "Yağmurlukla koşu yaparım", "Saunaya girerim" ve "Tükürerek kilo kaybederim" ile ergojenik yardımcilar alt boyutunda yer alan "Müshil hapları (ishal kesici) kullanırım", "Diyet hapları kullanırım" ve "İdrar söktürücü haplar kullanırım" sorularına verilen cevaplar arasında anlamlı bir farklılığa rastlanmamıştır (p>.05). 
Çimen, K. ve Göral, K. (2020). Büyükler serbest stil türkiye şampiyonasına katılan erkek güreşçilerin kilo düşme profillerinin incelenmesi. Spor Bilimleri Araştırmaları Dergisi, 5(2), 188-201.

Tablo 7. Güreşçilerin sıkletlerine göre verdikleri cevapların (fizyolojik etki, psikolojik etki) karşılaştırılması

\begin{tabular}{|c|c|c|c|c|c|}
\hline Alt boyutlar & & Sıkletler & Ort.Sira & $\mathbf{x}^{2}$ & $\mathbf{p}$ \\
\hline \multirow{15}{*}{ Fizyolojik etki } & \multirow{3}{*}{ Kas krampları yaşarım } & Hafif Siklet $(57-70 \mathrm{~kg})$ & 78,07 & \multirow{3}{*}{, 147} & \multirow{3}{*}{,929 } \\
\hline & & Orta Siklet $(74-86$ kg) & 77,03 & & \\
\hline & & Ağır Siklet (92-125 kg) & 74,88 & & \\
\hline & \multirow{3}{*}{ Vücut 1sım artar } & Hafif Siklet $(57-70 \mathrm{~kg})$ & 76,64 & \multirow{3}{*}{,793 } & \multirow{3}{*}{673} \\
\hline & & Orta Sıklet (74-86 kg) & 81,08 & & \\
\hline & & Ağır S1klet ( 92-125 kg) & 72,85 & & \\
\hline & \multirow{3}{*}{ Kalp çarpıntısı yaşarım } & Hafif Siklet (57-70 kg) & 75,90 & \multirow{3}{*}{, 364} & \multirow{3}{*}{,834 } \\
\hline & & Orta Siklet (74-86 kg) & 75,89 & & \\
\hline & & Ağır S1klet ( 92-125 kg) & 80,46 & & \\
\hline & \multirow{3}{*}{ Solunum güçlüğü çekerim } & Hafif Siklet (57-70 kg) & 76,96 & \multirow{3}{*}{, 001} & \multirow{3}{*}{1,000} \\
\hline & & Orta S1klet (74-86 kg) & 76,94 & & \\
\hline & & Ağır Siklet ( 92-125 kg) & 77,15 & & \\
\hline & \multirow{3}{*}{ Sakatlık yaşarım } & Hafif Siklet (57-70 kg) & 79,91 & \multirow{3}{*}{672} & \multirow{3}{*}{, 715} \\
\hline & & Orta S1klet (74-86 kg) & 73,75 & & \\
\hline & & Ağır S1klet ( 92-125 kg) & 75,20 & & \\
\hline \multirow{15}{*}{ Psikolojik etki } & \multirow{3}{*}{ Aşırı sinirli hale gelirim } & Hafif Siklet (57-70 kg) & 80,07 & \multirow{3}{*}{, 910} & \multirow{3}{*}{,635 } \\
\hline & & Orta S1klet (74-86 kg) & 75,94 & & \\
\hline & & Ağır S1klet ( 92-125 kg) & 72,08 & & \\
\hline & \multirow{3}{*}{ Aşırı yorgun hissederim } & Hafif Siklet (57-70 kg) & 75,24 & \multirow{3}{*}{, 319} & \multirow{3}{*}{, 853} \\
\hline & & Orta S1klet (74-86 kg) & 77,27 & & \\
\hline & & Ağır S1klet $(92-125 \mathrm{~kg})$ & 80,09 & & \\
\hline & \multirow{3}{*}{ Performansım düşer } & Hafif Siklet $(57-70 \mathrm{~kg})$ & 81,70 & \multirow{3}{*}{3,592} & \multirow{3}{*}{, 166} \\
\hline & & Orta Siklet (74-86 kg) & 78,82 & & \\
\hline & & Ağır S1klet ( 92-125 kg) & 65,69 & & \\
\hline & \multirow{3}{*}{ Strese girerim } & Hafif Siklet (57-70 kg) & 77,38 & \multirow{3}{*}{, 731} & \multirow{3}{*}{,694 } \\
\hline & & Orta S1klet (74-86 kg) & 80,34 & & \\
\hline & & Ağır S1klet ( 92-125 kg) & 72,28 & & \\
\hline & \multirow{3}{*}{ Spor yapma isteğim azalır } & Hafif Siklet (57-70 kg) & 75,22 & \multirow{3}{*}{2,011} & \\
\hline & & Orta Siklet (74-86 kg) & 84,34 & &, 366 \\
\hline & & Ağır S1klet ( 92-125 kg) & 71,73 & & \\
\hline
\end{tabular}

Araştırmaya katılan güreşçilerin verdikleri cevaplara göre, sıkletler arası alt boyutların karşılaştırılmasında sorulara verilen cevaplar arasında anlamlı bir farklılık bulunamamıştır (p>.05).

Tablo 8. Güreşçilerin "Karbonhidrat tüketimini azaltırım” cevaplarının sıkletlere göre karşılaştırılması

\begin{tabular}{cccc}
\hline (I) Sıklet & (J) Sıklet & Fark (I-J) & p \\
\hline Hafif Sıklet & Orta Siklet $(74-86 \mathrm{~kg})$ &, 09343 &, 966 \\
$(57-70 \mathrm{~kg})$ & Ağır Sıklet $(92-125 \mathrm{~kg})$ & $\mathbf{- , 6 6 5 1 7 ^ { * }}$ & $\mathbf{0 0 3}$ \\
\hline Orta Sıklet & Hafif Sıklet $(57-70 \mathrm{~kg})$ &,- 09343 &, 966 \\
$(74-86 \mathrm{~kg})$ & Ağır Sıklet $(92-125 \mathrm{~kg})$ & $\mathbf{- , 7 5 8 6 0}$ & $\mathbf{0 0 4}$ \\
\hline Ağır Sıklet & Hafif Sıklet $(57-70 \mathrm{~kg})$ & $\mathbf{, 6 6 5 1 7}^{*}$ & $\mathbf{0 0 3}$ \\
$(92-125 \mathrm{~kg})$ & Orta Siklet $(74-86 \mathrm{~kg})$ & $\mathbf{, 7 5 8 6 0}$ & $\mathbf{0 0 4}$ \\
\hline
\end{tabular}

Araştırmaya katılan güreşçilerin verdikleri cevaplara göre, sıkletler arası alt boyutların karşılaştırılmasında sadece diyet alt boyutu içerisinde yer alan "Karbonhidrat tüketimini azaltırım" cevapları arasında anlamlı bir farka rastlanmıştır $(\mathrm{p}<.05)$. Tablo 8'e bakıldığında, farklılı̆̆ yaratan grubun ağır sıklet güreşçiler olduğu, hem hafif sıklet hem de orta sıklet 
güreşçiler ile ağır sıklet güreşçiler arasında farklılık bulunduğu belirlenmiştir $(\mathrm{p}<.05)$. Diğer cevaplar arasında ise herhangi bir anlamlı farklılık bulunamamıştır.

Tablo 9. Hafif sıklet güreşçilerinin verdikleri cevaplara göre alt boyutlar arasındaki ilişkiler

\begin{tabular}{|c|c|c|c|c|c|}
\hline Alt boyutlar & & Fizyolojik etki & Psikolojik etki & $\begin{array}{c}\text { Ergojenik } \\
\text { yardımcılar }\end{array}$ & Diyet \\
\hline \multirow{3}{*}{ Psikolojik etki } & $\mathrm{r}$ &, $560^{* *}$ & & & \\
\hline & $\mathrm{p}$ &, 000 & & & \\
\hline & $\mathrm{n}$ & 72 & & & \\
\hline \multirow{3}{*}{ Ergojenik yardımcılar } & $\mathrm{r}$ &, 162 &,- 005 & & \\
\hline & $\mathrm{p}$ & ,175 & ,969 & & \\
\hline & $\mathrm{n}$ & 72 & 72 & & \\
\hline \multirow{3}{*}{ Diyet } & $\mathrm{r}$ & ,045 & ,214 &,- 217 & \\
\hline & $\mathrm{p}$ & ,707 &, 071 & ,068 & \\
\hline & $\mathrm{n}$ & 72 & 72 & 72 & \\
\hline \multirow{3}{*}{ Sıvı kaybı } & $\mathrm{r}$ &,- 064 & 171 & 108 &, 177 \\
\hline & $\mathrm{p}$ &, 594 &, 150 &, 365 &, 136 \\
\hline & $\mathrm{n}$ & 72 & 72 & 72 & 72 \\
\hline
\end{tabular}

Araştırmaya katılan hafif sıklet güreşçilerin verdikleri cevaplara göre alt boyutlar arasındaki ilişkiler incelendiğinde, fizyolojik etki ve psikolojik etki puanları arasında pozitif yönde anlamlı bir ilişkiye $(\mathrm{p}<.05)$ rastlanırken, diğer alt boyutlar arasında anlamlı bir ilişki bulunamamıştır.

Tablo 10. Orta sıklet güreşçilerinin verdikleri cevaplara göre alt boyutlar arasındaki ilişkiler

\begin{tabular}{|c|c|c|c|c|c|}
\hline Alt boyutlar & & Fizyolojik etki & Psikolojik etki & $\begin{array}{c}\text { Ergojenik } \\
\text { yardımcılar }\end{array}$ & Diyet \\
\hline \multirow{3}{*}{ Psikolojik etki } & $\mathrm{r}$ &, 578 $^{* *}$ & & & \\
\hline & $\mathrm{p}$ &, 000 & & & \\
\hline & $\mathrm{n}$ & 44 & & & \\
\hline \multirow{3}{*}{ Ergojenik yardımcılar } & $\mathrm{r}$ & ,003 & ,280 & & \\
\hline & $\mathrm{p}$ & ,982 & 065 & & \\
\hline & $\mathrm{n}$ & 44 & 44 & & \\
\hline \multirow{3}{*}{ Diyet } & $\mathrm{r}$ & ,336" & 045 &,- 051 & \\
\hline & $\mathrm{p}$ &, 026 &, 773 &, 742 & \\
\hline & $\mathrm{n}$ & 44 & 44 & 44 & \\
\hline \multirow{3}{*}{ Sıvı kaybı } & $\mathrm{r}$ & ,039 & ,199 &,- 124 & , 108 \\
\hline & $\mathrm{p}$ &, 800 & ,195 &, 424 & ,487 \\
\hline & $\mathrm{n}$ & 44 & 44 & 44 & 44 \\
\hline
\end{tabular}

Araştırmaya katılan orta sıklet güreşçilerin verdikleri cevaplara göre alt boyutlar arasındaki ilişkiler incelendiğinde, fizyolojik etki ile psikolojik etki ve diyet alt boyutları arasında pozitif yönde anlamlı bir ilişkiye $(\mathrm{p}<.05)$ rastlanırken, diğer alt boyutlar arasında anlamlı bir ilişki bulunamamıştır.

Tablo 11. Ağır sıklet güreşçilerinin verdikleri cevaplara göre alt boyutlar arasındaki ilişkiler

\begin{tabular}{|c|c|c|c|c|c|}
\hline Alt boyutlar & & Fizyolojik etki & Psikolojik etki & $\begin{array}{c}\text { Ergojenik } \\
\text { yardımcılar }\end{array}$ & Diyet \\
\hline \multirow{3}{*}{ Psikolojik etki } & $\mathrm{r}$ & 297 & & & \\
\hline & $\mathrm{p}$ & 074 & & & \\
\hline & $\mathrm{n}$ & 37 & & & \\
\hline \multirow{3}{*}{ Ergojenik yardımcılar } & $\mathrm{r}$ & ,441** & ,412* & & \\
\hline & $\mathrm{p}$ &, 006 &, 011 & & \\
\hline & $\mathrm{n}$ & 37 & 37 & & \\
\hline \multirow{3}{*}{ Diyet } & $\mathrm{r}$ & 071 &, 104 & ,245 & \\
\hline & $\mathrm{p}$ & 675 & ,540 & 144 & \\
\hline & $\mathrm{n}$ & 37 & 37 & 37 & \\
\hline \multirow{3}{*}{ Sıvı kaybı } & $\mathrm{r}$ & ,030 & ,051 &,- 025 &,- 282 \\
\hline & $\mathrm{p}$ & ,858 & ,766 &, 883 & ,091 \\
\hline & $\mathrm{n}$ & 37 & 37 & 37 & 37 \\
\hline
\end{tabular}


Araştırmaya katılan ağır sıklet güreşçilerin verdikleri cevaplara göre alt boyutlar arasındaki ilişkiler incelendiğinde, ergojenik yardımcılar ile fizyolojik etki ve psikolojik etki alt boyutları arasında pozitif yönde anlamlı bir ilişkiye $(\mathrm{p}<.05)$ rastlanırken, diğer alt boyutlar arasında anlamlı bir iliş̧i bulunamamıştır.

\section{TARTIŞMA VE SONUÇ}

Büyükler Türkiye şampiyonasına katılan erkek güreşçilerin kilo kaybı profillerinin sıkletlere göre incelenmesi amacıyla yapılan bu çalışmaya katılan güreşçilerin $\% 47,1$ 'ini hafif sıklet, $\% 28,8$ 'ini orta sıklet, \%24,2'sini ise ağır sıklet sporcular oluştururken tüm sıkletlerdeki güreşçilerin çok büyük bir çoğunluğu, müshil, diyet ve idrar söktürücü gibi haplar kullanmayı tercih etmediklerini belirtmişlerdir. Kilo düşme yöntemlerinin tercih edilmesi bakımından diyet alt boyutunda yer alan yăg tüketiminin azaltılmasının (ağır sıklet \%54,1; orta sıklet \%37,2; hafif sıklet \%35,6) en çok tercih edilen cevap olduğu belirlenmiştir. Araştırmada elde edilen bulgulara göre, sıkletler arası alt boyutların karşılaştırılmasında sadece diyet alt boyutu içerisinde yer alan "Karbonhidrat tüketimini azaltırım" cevapları arasında anlamlı bir farka rastlanmıştır $(\mathrm{p}<.05)$. Farklılığı yaratan grubun ise ağır sıklet güreşçiler olduğu, hem hafif sıklet hem de orta sıklet güreşçiler ile ağır sıklet güreşçiler arasında farklılık bulunduğu belirlenmiştir $(\mathrm{p}<.05)$. Diğer cevaplar arasında ise herhangi bir anlamlı farklılık bulunamamıştır ( $p>.05)$.

Xiong vd., (2017) tarafından Malezya' daki elit dövüş sporcuları üzerinde yaptıkları çalışmada, sporcular arasında hızlı kilo düşmenin oldukça yaygın olduğu $(\% 92,5)$, terletici elbiselerle antrenman $(\% 62,2)$ ve öğün atlamanın $(\% 27,0)$ uygulanan en yaygın hızlı kilo düşme teknikleri olduğu tespit ederlerken, elit dövüş sporcuları arasındaki yüksek düzeyde agresif kilo kaybı prevalansının ortaya çıkmasının büyük bir endişe kaynağı olduğuna da vurgu yapmışlardır. Yarar, Türkyılmaz, Eroğlu, Kurt ve Eskici (2017) tarafından elit güreşçiler üzerinde yapılan bir çalışmada da, güreşçilerin kilo düşme yöntemleri açısından, hızlı bir şekilde kilo düşmeye sebebiyet veren müshil ilaçları, zayıflama hapları ve idrar söktürücü hapları kullanmayı tercih etmedikleri belirlenmiştir. Yağmur, Iş1k, Kılıç ve Doğan (2019), elit grekoromen güreşçilerde kilo düşme yöntemlerini inceledikleri çalışmalarında, güreşçilerin \%92,9'unun yiyecek tüketimini, \%87,1'inin karbonhidrat tüketimini, \%95,7'sinin ise yă̆ tüketimini azaltırım cevabı verdikleri tespit edilmiştir. Buschmann ve Cuff (2016), karbonhidratların sporcular için önemine dikkat çekerek, sporcuların düşük karbonhidratlı diyetlerden kaçınması gerektiğini, bir sporcunun antrenmanlarını yapabilmesi için gerekli olan enerjiyi sağlaması için karbonhidratlara ihtiyacı olduğunu, kilonun kontrol edilmesi için karbonhidrat alımının sınırlandırılmasının düşük enerji ve zihinsel yorgunluğa sebebiyet vereceğini belirtmişlerdir. Ersoy ve Hasbay (2008), sporcuların, azalan ya da boşalan karbonhidrat depoları ile antrenmanlarını sürdürmeye çalışmalarının, sakatlık ve yaralanma riskini de artıran önemli bir faktör olduğuna dikkat çekmektedirler.

Oppliger, Nelson Steen ve Scott (2003) tarafından yapılan ve güreşçilerin kilo yönetimi davranışlarının incelendiği çalışmada, antrenörlerin ve güreşçilerin kilo verme yöntemleri üzerinde birincil derecede etkiye sahip olduklarını belirterek, bildirilen temel kilo kaybı yönteminin kademeli olarak yapılan diyet (\%79.4) olduğuna vurgu yapmışlardır. Satıcı, Akyol, İmamoğlu ve Ermiş (2017) tarafından judo ve güreşçilerde kilo düşme üzerine yapılan bir çalışmada da, müsabaka tartısı öncesinde kilo düşme yöntemi olarak en çok \% 35,3 ile koşuya 
başvurulduğunu, sauna yönteminin de \%29,4 ile hemen sonrasında geldiğini belirtirlerken, kilo düşme konusunda her iki branşta yer alan sporcuların da doğru bir yaklaşıma sahip olmadıkları sonucuna ulaşmışlardır. Yarar ve diğerleri (2017) tarafından yapılan bir çalı̧̧mada, elit güreşçilerin en çok tercih ettikleri kilo düşme yöntemlerinin, \%33 oranında yağ tüketiminin azaltılması ve \%31 oranında yağmurlukla koşu olduğu tespit edilmiştir. Koç ve Türkçapar'ın (2015) elit güreşçiler üzerine yaptıkları çalışmada, güreşçilerin sıvı tüketimi konusunda dikkatli oldukları $(\% 63,3)$ ve \%73,9'unun da beslenme destek ürünlerini kullanmadığı, kullananların ise \% 72,3'ünün performans geliştirme amacıyla kullandıkları belirlenmiştir. Kurt ve Sağıroğlu (2015) Türk sporcular üzerinde hızlı kilo düşme üzerine yaptıkları çalışmada, hızlı kilo düşme yöntemleri arasında en çok kullanılanların, $\% 75$ oranında antrenmanlarda kat kat giyinme, \%64,3 oranında öğün atlama, \%63,4 oranında aç kalma ve \%58 oranında saunaların yer aldığın, hızlı kilo düşülen bu dönemde en çok algılanan problemlerin, aşırı yorgunluk (\% 70.5), fiziksel performansta düşüş (\% 67.9) ve sinirlilik (\%66.1) olduğunu tespit etmişlerdir. İmamoğlu, Soygüden ve Türkmen'in (2017) güreşçiler ve judocularda kilo kaybı durumları üzerine yaptıkları çalışmada, kilo düşülmeyen müsabakalarda başarılı olan sporcuların oranının daha yüksek olduğu, ancak sporcuların bilinçsizce kilo düşme eğiliminde oldukları, her iki branşta yer alan sporcuların da kilo kayıplarının farkında olmalarının gerektiği belirtilmiştir.

Yamak (2019) elit güreş ve judo sporcularında kilo düşme ile ilgili yaptı̆̆ çalışmada, sporcuların vücut ağırlıklarının $\% 3$ ile \%7 arasındaki kilo düşmelerinin esneklik özelliklerinde önemli bir değişime yol açmadığını, ancak aerobik ve anaerobik güç özelliklerinde düşüşe sebebiyet verdiğini belirtirken, sporcuların kilo düşmemeye teşvik edilmesini, eğer kilo düşülecek ise de bunun uzun vadeye yayılmasının gerektiğini önermektedir. Yarar ve diğerleri (2017) tarafından yapılan bir çalışmada, elit güreşçilerin \%35,9'unun müsabakaya iki hafta kala, \%26,6'sının ise müsabakaya bir hafta kala kilo düşmeye başladıkları belirlenmiştir. Książek, Karpała ve Słowińska-Lisowska (2017), Polonyalı Milli judo sporcularında müsabaka öncesi dönemde kilo düşme durumlarını incelemek amacıyla yaptıkları çalışmada, diyet bileşenlerinin günlük ortalama alımlarının (enerji, karbonhidratlar, diyet lifi, proteinler, yağlar, su, mineraller ve vitaminler) sporcular için önerilen normlardan önemli ölçüde farklı seviyede olduğunu, judocuların önerilen normlara kıyasla daha az enerji, daha az karbonhidrat, daha az yağ, daha az su, potasyum, kalsiyum, demir, iyot, vitamin (D, C, E, B2) tükettiklerini, diğer taraftan da, sodyum, fosfor, vitamin (B3, B6, B12) diyet alımının önerilen normdan önemli ölçüde daha yüksek olduğunu tespit etmişlerdir.

Çatıkkaş (2016), genç taekwondo sporcularının sağlıksız kilo verme davranışlarını incelediği çalışmasında, en çok tercih edilen hızlı kilo düşme yöntemlerinin, aç kalma, katkat giyinme, sauna, öğün atlama, tek tip beslenme ve yağ yakıcı ilaç kullanımının olduğunu, hızlı kilo verme yönteminin seçiminde ise sporcunun kendisi, arkadaşı ve antrenörünün etkili kaynaklar olarak belirlendiğini ifade ederken, hızlı kilo düşme yöntemlerine bağlı olarak gerçekleştĭgi tespit edilen ölümlerin bulunmasına rağmen sporcuların hala daha sağlıksız şekilde kilo düşme yöntemlerini kullanmaya devam etmesinin, bu konu üzerinde acil olarak çeşitli önlemlerin alınması gerekliliğini de beraberinde getirdiğine vurgu yapmıştır. Işık, Gökdemir, Bastık, Yıldırım ve Doğan (2013) yaptıkları çalışmada, dehidrate olan sporcularda düşülen kilo miktarı ile depresyon düzeyi arasında pozitif yönlü bir ilişki bulunduğu, düşülen kilo miktarında yükselme meydana geldikçe depresyon düzeylerinin de arttığı sonucuna ulaşmışlardır. Yarar 
vd., (2017) tarafından yapılan bir çalışmada, güreş sporcularının erken yaşlarda kilo düşmeye başladıkları ve güreşçilerin büyük bir kısmının da müsabakanın başlangıcına çok az bir zaman kalmış olmasına rağmen hızlı kilo düşme yöntemlerini kullanarak ulaşmak istedikleri vücut ağırlığına erişmeye çabaladıkları belirlenmiştir.

Tekbaş, İmamoğlu ve Atan (2017) yaptıkları çalışmada, aşırı kilo düşmelerin sakatlık riskini artırabileceğine vurgu yapmışlar ve düzgün beslenememenin de güreş sporcularında sakatlanmayı hazırlayıcı faktörler arasında göstermişlerdir. Ersoy ve Hasbay (2008), sporcular için sağlıklı olan vücut ağırlığının sürdürülebilir olmasına dikkat çekerek, bu ağırlığın, performansı olumsuz etkilemeyen, sakatlık ve hastalık riski oluşturmayan bir yapıda olması gerektiğini belirtmişlerdir. Işık vd., (2013) tarafından elit güreşçiler konusunda yapılan bir çalışmada, sıklet sporlarında, sporcuların genellikle hızlı bir şekilde kilo düşmekte olduklarını ve bu kilo düşmeleri, sauna, sıvı ve besin kısıtlaması yoluyla yapan sporcuların dehidrasyona maruz kaldıklarına vurgu yapılmaktadır.

Çolak, Şahin, Soylu, Koç ve Öcal (2020) kilo verme yöntemleri üzerine yaptıkları çalışmalarında, yarışma öncesinde sporcuların kilo düşme durumları ile vücut ağırlıklarının düzenli olarak kontrol altında tutulmasının, sporcu sağlığı ve sporcuların performansları açısından oldukça yararlı olduğuna vurgu yaparlarken, İşler (2012) de, hızlı şekilde meydana gelen kilo kaybının sporcuyu ağır bir dezavantaja sürükleyebileceğini, bunun yanı sıra hiçbir sporcunun bedeninin gereğinden fazla su kaybına uğradığı zaman en iyi performansına ulaşamayacağını belirtmektedir.

Araştırmadan elde edilen bulgulardan hareketle, Büyükler Türkiye Şampiyonasına katılan güreşçilerde, kilo düşme profili olarak, vücuttan yağ kaybı, sıvı kaybı, yiyecek ve karbonhidrat tüketimini azaltma eğilimlerinin genellikle tercih edilen stratejiler olduğu görülmektedir. Sonuç olarak, sıklet sporu yapan bireylerde, kalori dengesinin korunabilmesinin performansı etkileyen önemli bir unsur olduğu düşüncesinden hareketle, güreşçilere ve antrenörlerine kilo düşme yöntemleri ve kilo kontrolü hakkında seminer imkanlarının sağlanması ve bilgi düzeylerinin geliştirilmesinin, sporcuların istenilen seviyedeki yüksek performans seviyesine ulaşabilmesi için oldukça önemli katkılar sağlayacağı söylenebilir. 
Çimen, K. ve Göral, K. (2020). Büyükler serbest stil türkiye şampiyonasına katılan erkek güreşçilerin kilo düşme profillerinin incelenmesi. Spor Bilimleri Araştırmaları Dergisi, 5(2), 188-201.

\section{KAYNAKLAR}

Buschmann, J. \& Cuff, S. (2016). Weight Loss Practices and Nutrition in Wrestlers. Ohio Pediatrics, Sports Shorts Guidelines for Parents, Winter, 2016.

Cicioğlu, İ., Kürkçü, R., Eroğlu, H. ve Yüksek, S. (2007). 15-17 Yaş gurubu güreşçilerin fiziksel ve fizyolojik özelliklerinin sezonsal değişimi. Spormetre Beden Eğitimi ve Spor Bilimler Dergisi, 5(4), 151-56. https://doi.org/10.1501/Sporm_0000000085.

Çamçakal, A., Pepe, H., \& Altın, M. (2014). Aerobic and Anaerobic Power Profile of Elite Turkish Greco-Roman Wrestlers. Niğde University Journal of Physical Education and Sport Sciences, 8(3), 251-260.

Çatıkkaş, F. (2016). Genç taekwondo sporcularının sağlıksız kilo verme davranışları. CBÜ Beden Eğitimi ve Spor Bilimleri Dergisi, 11(2), 125-130.

Çolak, A., Şahin, İ., Soylu, Y., Koç, M., \& Öcal, T. (2020). Weight loss methods and effects on the different combat sports athletes. Progress in Nutrition, 22, 1-S, 119-124. https://doi.org/10.23751/pn.v22i1S.9803.

Demirci, N. (1995). A'dan Z'ye spor. Ankara: Neyir Yayıncılık ve Matbaacılık.

Ersoy, G. ve Hasbay, A. (2008). Sporcu beslenmesi. Ankara: Klasmat Matbaacılık, Sağlık Bakanlığı Yayın No: 726.

Işık, Ö., Gökdemir, K., Bastık, C., Yıldırım, İ. \& Doğan, İ. (2013). Elit güreşçiler üzerine bir çalışma: Ağırlık kaybı ve depresyon. Beden Eğitimi ve Spor Bilimleri Dergisi, 7(3), 216-223.

İmamoğlu, O., Soygüden, A. \& Türkmen, M. (2017). Comparison of female wrestler and female judokas' weight loss situations. International scientific and professional conference on wrestling: "Applicable research in wrestling" proceeding books, pp. 181-187, Novi Sad, Serbia.

İşler, H. (2012). Beden eğitimi ve spor bilgileri rehber kitabı. İstanbul: Bedray yayınları.

Koç, M. ve Türkçapar, Ü. (2015). Elit Güreşçilerin beslenme alışkanlıkları ve beslenme destek ürünü kullanma durumlarının incelenmesi. Akademik Sosyal Araştırmalar Dergisi, 3(21), 503-514. http://dx.doi.org/10.16992/ASOS.867.

Książek, A., Karpała, J. \& Słowińska-Lisowska, M. (2017). An evaluation of diets in the Polish national judo team during the pre-competition weight loss period. Arch Budo, 13: 101-106.

Kurt, C. ve Sağıroğlu, İ. (2015). Rapid weight loss practice and perceived problems during reduction periods of Turkish young combat athletes. Journal of Physical Education and Sport, 15(4), 748-751. http://dx.doi.org/10.7752/jpes.2015.04114.

Oppliger, R.A., Nelson Steen, S.A. \& Scott, J.R. (2003). Weight loss practices of college wrestlers. International Journal of Sport Nutrition and Exercise Metabolism, 13(1), 29-46.

Satıc1, A., Akyol, P., İmamoğlu, O. \& Ermiş, E. (2017). Judo ve Güreşçilerde kilo düşme periyodunda antrenman ve beslenme durumlarındaki değişimin araştıılması. 15.Uluslararası Spor Bilimleri Kongresi, 15-18 Kasım, pp.129-130, Antalya.

Tekbaş, B., İmamoğlu, O. \& Atan, T. (2017). Güreş branşında sakatlıklar ve önlenmesi. Uluslararası Türk Halkları Geleneksel Oyunlar - Sporlar Sempozyumu Bildiri Kitapçı̆̆̆, s.242-246, 8-10 Aralık, Kahramanmaraş. 
Çimen, K. ve Göral, K. (2020). Büyükler serbest stil türkiye şampiyonasına katılan erkek güreşçilerin kilo düşme profillerinin incelenmesi. Spor Bilimleri Araştırmaları Dergisi, 5(2), 188-201.

Xiong, N.Q., Xian, C.Y., Karppaya, H., Jin, C.W. \& Ramadas, A. (2017). Rapid weight loss practices among elite combat sports athletes in Malaysia. Malaysian Journal of Nutrition, 23(2), 199-209.

Yağmur, R., Işık, Ö., Kılıç, Y. \& Doğan, I. (2019). Weight loss methods and effects on the elite cadet grecoroman wrestlers. JTRM in Kinesiology, 5, 33-40.

Yamak, B. (2019). Elit güreş ve judocularda kilo düşme ile esneklik, aerobik ve anaerobik güç değerleri değişimi. Spor Ĕ̈itim Dergisi, 3(1), 10-16.

Yarar, H., Türkyılmaz, R., Eroğlu, H., Kurt, S. \& Eskici, G. (2017). Elit güreşçilerin kilo düşme profillerinin incelenmesi. Atatürk Üniversitesi Beden Eğitimi ve Spor Bilimleri Dergisi, 19(4), 52-63.

Yarar, H., Eroğlu, H., Üzüm, H. \& Polat, E. (2016). Sporcu kilo düşme yöntemleri ve etkileri ölçeği: Geçerlik ve güvenirlik çalışması. Journal of Human Sciences, 13(3), 6164-6175.

Bu eser Creative Commons Atıf-GayriTicari 4.0 Uluslararası Lisansı ile lisanslanmıştır. 